\section{Instrumental Activities of Daily Living}

Tamara Bushnik

Director of Inter-Hospital Research and

Knowledge Translation, Rusk Rehabilitation, New York, NY, USA

\section{Synonyms}

IADLs

\section{Definition}

Instrumental activities of daily living are a subset of activities of daily living (ADLs). They include activities that are required to live independently, such as cooking and shopping. They are contrasted with basic activities of daily living (bADLs), which include basic self-care functions such as eating and bathing.

\section{Cross-References}

- Activities of Daily Living (ADLs)

- Basic Activities of Daily Living (BADLs)

\section{References and Reading}

Instrumental activities of daily living. (2009). Mosby's medical dictionary (8th ed.). http://medical-dictionary. thefreedictionary.com/instrumental+activities + of + daily +living. Retrieved from 29 Feb 2016.

Instrumental activities of daily living. (2012). Medical dictionary for the health professions and nursing. http://medi cal-dictionary.thefreedictionary.com/instrumental+activi ties + of + daily+living. Retrieved from 29 Feb 2016.

Katz, S. (1983). Assessing self-maintenance: Activities of daily living, mobility, and instrumental activities of daily living. Journal of the American Geriatric Society, 31, 331-341.

Lawton, M. P., \& Brody, E. M. (1969). Assessment of older people: Self-maintaining and instrumental activities of daily living. Gerontologist, 9, 179-186. 